\title{
Selective Oxidation of Diphenylmethane to Benzophenone over CeAIPO-5 Molecular Sieves
}

\author{
Subbiah DEVIKA, Muthiahpillai PALANICHAMY, Velayutham MURUGESAN* \\ Department of Chemistry, Anna University, Chennai 600 025, India
}

\begin{abstract}
Selective oxidation of diphenylmethane to benzophenone requires active and selective catalysts. The framework incorporation of cerium in AlPO-5 molecular sieves creates active cerium sites in isolation. These active sites are responsible for selective oxidation. Cerium incorporated AlPO-5 with different $\mathrm{Al} / \mathrm{Ce}$ ratios were synthesized, and the vapor phase oxidation of diphenylmethane in air over these catalysts was studied at $250,275,300,325$, and $350^{\circ} \mathrm{C}$. The diphenylmethane conversion and selectivity for benzophenone were more than $90 \%$. CeAIPO-5(25) was found to be more active than other catalysts. The stability of the catalyst was verified by the time on stream study which indicated steady diphenylmethane conversion and benzophenone selectivity. Hence framework incorporated CeAlPO-5 molecular sieves are stable and active catalysts for the selective oxidation of diphenylmethane.
\end{abstract}

Key words: CeAlPO-5 molecular sieve; hydrothermal synthesis; oxidation; diphenylmethane; benzophenone

CLC number: O643 Document code: A

Received 26 September 2011. Accepted 13 January 2012.

*Corresponding author. Tel: +91-44-22357023/22358645; Fax: +91-44-2220066/22201213; E-mail: v_murugu@hotmail.com

This work was supported by the Department of Science and Technology (DST, SR/S1/PC-10/2009), Government of India, New Delhi, and the University Grants Commission (UGC), New Delhi.

English edition available online at Elsevier ScienceDirect (http://www.sciencedirect.com/science/journal/18722067).

Oxidation of diphenylmethane (DPM) to benzophenone is an industrially important reaction as the product benzophenone is used as an intermediate in the synthesis of perfumes, photoinitiators, drugs, and pharmaceuticals [1]. Generally, benzophenone has been prepared by Friedel-Crafts acylation of benzene with benzoyl chloride in the presence of a Lewis acid catalyst [2-6]. This process is homogeneous, hazardous, corrosive, and the catalyst cannot be recovered easily for recycling. Further, the catalyst is deactivated and it can not be easily disposed off. Manganese(III) Schiff base complex is an efficient homogeneous catalyst for the oxidation of DPM with $30 \% \mathrm{H}_{2} \mathrm{O}_{2}$ in acetonitrile under ambient condition and it resulted $69 \%$ benzophenone [7]. Since this is a homogeneous process, separation of the product from the reaction mixture is difficult. It is, therefore, of great practical interest to develop a heterogeneous, efficient, easily separable, reusable, and eco-friendly catalyst for the production of aromatic ketones. In contrast to benzoylation of benzene, oxidation of DPM over heterogeneous catalyst is an eco-friendly alternative for industrial production of benzophenone.

The survey of literature revealed reports on the oxidation of DPM using different heterogeneous catalysts. Clark et al. [8] reported the first heterogeneous catalyzed oxidation of DPM to benzophenone over alumina supported chromium and manganese. Shaabani et al. [9] reported solvent free oxidation of DPM over $\mathrm{KMnO}_{4}$ supported montmorillonite $\mathrm{K} 10$ with good yield of benzophenone. But the process is hazardous. The selective oxidation of DPM over $\mathrm{KMnO}_{4}$ impregnated on alumina under microwave irradiation in dry media was studied by Oussaid and Loupy [10]. This process is not only hazardous but also not suitable for long term use. Although sodium chlorite $\left(\mathrm{NaClO}_{2}\right)$ was effectively used as a selective catalyst for DPM oxidation either in combination with tert-butylhydroperoxide (TBHP) in stoichiometric quantity or with $N$-hydroxyphthalimide [11], this process is also hazardous. Mn-MCM-41 catalysts were reported for DPM oxidation using air as the oxidant. However, the yield of benzophenone was low [12]. Low DPM conversion $(12 \%-15 \%)$ and poor selectivity were observed over metal incorporated M-MCM-41 (where $\mathrm{M}$ is $\mathrm{Ti}, \mathrm{V}$, and $\mathrm{Cr}$ ) using $\mathrm{H}_{2} \mathrm{O}_{2}$ as oxidant and acetonitrile as solvent at $60{ }^{\circ} \mathrm{C}$ for $12 \mathrm{~h}$ [13]. The direct oxidation of DPM to benzophenone was also studied over cobalt-doped MCM-41 (Co/MCM-41) and cobalt-doped mesoporous $\mathrm{TiO}_{2}\left(\mathrm{Co} / \mathrm{MTiO}_{2}\right)$ [14]. Chang et al. [15] reported that cobalt-doped MCM-41 (Co/MCM-41) is a highly selective catalyst for the direct oxidation of DPM to benzophenone employing $\mathrm{H}_{2} \mathrm{O}_{2}$ as the oxidant in acetic acid. It was reported that $\mathrm{MnO}_{4}^{-}$exchanged Mg-Al-hydrotalcite showed good selectivity in the oxidation of DPM [16]. Kishore and Rodrigues [17] carried out liquid phase oxidation of DPM over ternary hydrotalcites with TBHP as 
oxidant using different solvents, and they reported $95 \%$ DPM conversion with $100 \%$ selectivity for benzophenone. However, TBHP is a sacrificial and hazardous oxidant. The literature revealed the use of solvents or hazardous materials for the oxidation of DPM. Impregnated ceria was examined for the oxidation of alkyl aromatics $[18,19]$. Though the catalyst is active, its sintering nature at high temperature is a drawback [20]. The problem of sintering can be circumvented by incorporation of cerium into the framework of porous molecular sieves. In addition, such framework incorporated catalysts can combine the high selective characteristics of homogeneous catalysts as well as the recovery and recyclability of heterogeneous catalysts. Hence the present study focused on the synthesis of CeAlPO-5 and its catalytic evaluation in the oxidation of DPM in air.

\section{Experimental}

\subsection{Synthesis of catalysts}

The procedure followed by Zhao et al. [21] was slightly modified and adopted for the synthesis of CeAlPO-5 molecular sieves. The modifications were high crystallization time and presence of varying amount of isopropyl alcohol derived from aluminium source. These two modifications enhanced the crystallinity of materials. The following gel composition was used for the synthesis: $x \mathrm{Ce}\left(\mathrm{NO}_{3}\right)_{3} \cdot 6 \mathrm{H}_{2} \mathrm{O}$ : $1.0 \mathrm{Al}_{2} \mathrm{O}_{3}: 1.3 \mathrm{P}_{2} \mathrm{O}_{5}: 1.6 \mathrm{TEA}: 1.3 \mathrm{HF}: 425 \mathrm{H}_{2} \mathrm{O}$. Aluminium isopropoxide (7.151 g, Merck) was soaked in $50 \mathrm{ml}$ deionized water for $24 \mathrm{~h}$ and stirred for $2 \mathrm{~h}$. Orthophosphoric acid (4.9 $\mathrm{g}$, Merck), triethylamine (2.8 g, Merck), and cerium nitrate hexahydrate $(0.60 \mathrm{~g}$, Fluka) were dissolved in appropriate amount of water and stirred separately for $2 \mathrm{~h}$ at $30^{\circ} \mathrm{C}$. The aluminium precursor was added to the above mixture and stirred for $2 \mathrm{~h}$. Dilute hydrofluoric acid (0.93 g, Merck) was then added and the mixture was stirred again for another 2 h. Finally, the gel was transferred to a Teflon-lined stainless steel autoclave and heated at $180{ }^{\circ} \mathrm{C}$ for $6 \mathrm{~h}$ under static condition. After quenching the hot autoclave in cold water, the crystallized product was recovered by filtration, dried in an oven at $110{ }^{\circ} \mathrm{C}$ and calcined at $550{ }^{\circ} \mathrm{C}$ in air for $5 \mathrm{~h}$ at a heating rate of $1{ }^{\circ} \mathrm{C} / \mathrm{min}$. The catalysts were denoted as CeAlPO-5(x), where $x$ was $\mathrm{Al} / \mathrm{Ce}$ ratio.

The same procedure was also adopted for the synthesis of AlPO-5 without cerium precursor.

\subsection{Characterization of catalysts}

The X-ray diffraction (XRD) patterns of the synthesized materials were recorded on a PANalytical X'pert PRO diffractometer equipped with $\mathrm{Cu} K_{\alpha}(0.154 \mathrm{~nm})$ as the radiation source and a liquid nitrogen cooled germanium solid state detector. The samples were scanned from $5^{\circ}$ to $40^{\circ}$ $(2 \theta)$ in steps of $0.02^{\circ}$ with a count time of $5 \mathrm{~s}$ at each point. Fourier transform infrared (FT-IR) spectra of the samples were recorded in the range of 4000 to $400 \mathrm{~cm}^{-1}$ on an FT-IR spectrometer (Nicolet, Avatar 360) using $\mathrm{KBr}$ pellet technique. Thermogravimetric analysis (TGA) of the materials was carried out under nitrogen atmosphere in the temperature range of 30 to $1000{ }^{\circ} \mathrm{C}$ at a heating rate of $10{ }^{\circ} \mathrm{C} / \mathrm{min}$ on an SDTQ-600 WATERS system. Thermogravimetric analysis of the materials was also carried out in air atmosphere in the temperature range from 30 to $1000{ }^{\circ} \mathrm{C}$ at a heating rate of $10^{\circ} \mathrm{C} / \mathrm{min}$ on an SDTQ-600 V8.3 Build 101 model system. Surface area of the sample was carried out by nitrogen adsorption at $-196{ }^{\circ} \mathrm{C}$ on an ASAP-2020 porosimeter from Micromeritics Corporation (Norcross, GA, USA). Before nitrogen adsorption-desorption measurement, each sample was degassed for $3 \mathrm{~h}$ at $250{ }^{\circ} \mathrm{C}$ under vacuum $\left(10^{-5} \mathrm{mbar}\right)$ in the degas port of the adsorption analyzer. The ultraviolet-visible diffuse reflectance spectra (UV-Vis DRS) of the samples were recorded in the range of 200 to 800 $\mathrm{cm}^{-1}$ using JASCO V-550 instrument. The Raman spectra were recorded using Raman Spectrometer 785L (ASPIRE). The morphology of the samples was examined by scanning electron microscope (SEM). The sample was suspended in methanol and the specimen stub dipped into it and removed. Evaporation of methanol left the sample evenly dispersed on the stub. The sample was coated with gold by ion sputtering for $2 \mathrm{~min}$ and the SEM image was recorded using HITACHI-S-3400N instrument. The $\mathrm{Al} / \mathrm{Ce}$ ratios of the samples were determined by energy dispersive X-ray analyzer (EDAX) housed in the same SEM unit. The electron paramagnetic resonarce (ESR) spectra were recorded on a Bruker EMX Plus spectrophotometer at room temperature with microwave power of $0.632 \mathrm{~mW}$ and modulation frequency of $100 \mathrm{kHz}$. X-ray photoelectron spectra (XPS) of the samples were performed on a Thermo Multilab 2000 using monochrome $\mathrm{Al} K_{\alpha}$ as the excitation source.

\subsection{Catalytic studies}

The vapor phase oxidation of DPM (Merck) was carried out in a fixed-bed vertical downward flow glass reactor of internal diameter $2 \mathrm{~cm}$. About $0.5 \mathrm{~g}$ of the catalyst was placed at the center of the reactor, and it was supported on either side with a thin layer of quartz wool and ceramic beads. The reactor was heated to the requisite temperature using a temperature-programmed furnace. The catalyst was activated before each reaction at $500{ }^{\circ} \mathrm{C}$ for $6 \mathrm{~h}$ in a controlled stream of carbon dioxide free air. The reactant was fed into the reactor using a syringe infusion pump. The products were collected in the receiver flask and analyzed using a gas chromatograph (Shimadzu 17A) equipped with 
a DB-5 capillary column $(30 \mathrm{~m} \times 0.25 \mathrm{~mm} \times 0.25 \mu \mathrm{m})$ and a flame ionization detector. The products were also identified using a GC-MS (Perkin Elmer Clarus 500) with helium as the carrier gas at a flow rate of $1 \mathrm{ml} / \mathrm{min}$.

\section{Results and discussion}

\subsection{Characterization results}

\subsubsection{XRD}

The XRD patterns of the calcined AlPO- 5 and CeAlPO-5 with different $\mathrm{Al} / \mathrm{Ce}$ ratios are shown in Fig. 1. There are no extra peaks present other than the peaks corresponding to AlPO-5, thus confirming the absence of free ceria phase [22]. The lattice parameters and the positions of reflections

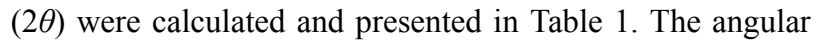
positions of the reflections of AlPO-5 and CeAlPO-5 showed a shift in the $2 \theta$ values, and change in the lattice parameters compared to AlPO-5, thus supporting framework substitution of cerium. The intensity of the reflection at $2 \theta=$ $7.4^{\circ}$ for all CeAlPO-5 molecular sieves was higher than that of the parent AlPO-5. Hence, (100) plane is better for cerium incorporation than that of other planes. The intensity of this reflection was higher for CeAlPO-5 than AlPO-5 due to larger atomic size of cerium than aluminium.

\subsubsection{FT-IR}

The FT-IR spectra of the calcined CeAlPO-5 samples are shown in Fig. 2. In Fig. 2(1), the intense broad band between 2500 and $4000 \mathrm{~cm}^{-1}$ was due to $-\mathrm{OH}$ stretching vibration of water. The corresponding bending vibration occurred at $1667 \mathrm{~cm}^{-1}$. The absence of peak due to $-\mathrm{CH}_{2}-$ vibrations just below $3000 \mathrm{~cm}^{-1}$ confirmed the complete removal of template. The peaks around $2280 \mathrm{~cm}^{-1}$ were due to $\mathrm{CO}_{2}$ in air. The asymmetric and symmetric stretching vibrations of Al-O-P occurred between 800 and $1500 \mathrm{~cm}^{-1}$. The corresponding bending vibration occurred at $735 \mathrm{~cm}^{-1}$. Similar stretching vibrations were also reported for M-AlPO-5 (M = La, Ce, Sm, Dy, Y, Gd) [22]. The FT-IR spectra of calcined CeAlPO-5 $(x=50,75,100$, and 125)

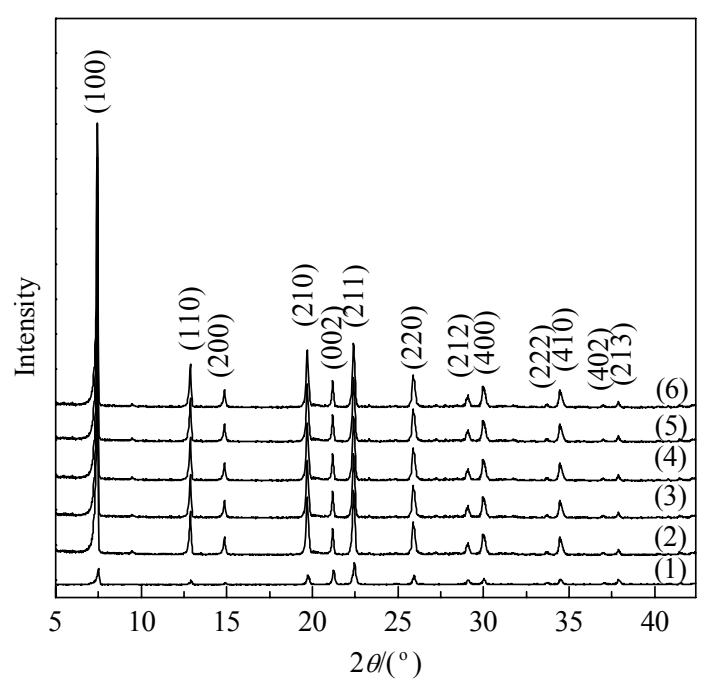

Fig. 1. XRD patterns of the calcined AlPO-5 and CeAlPO-5. (1) AlPO-5; (2) CeAlPO-5(25); (3) CeAlPO-5(50); (4) CeAlPO-5(75); (5) CeAlPO-5(100); (6) CeAlPO-5(125).

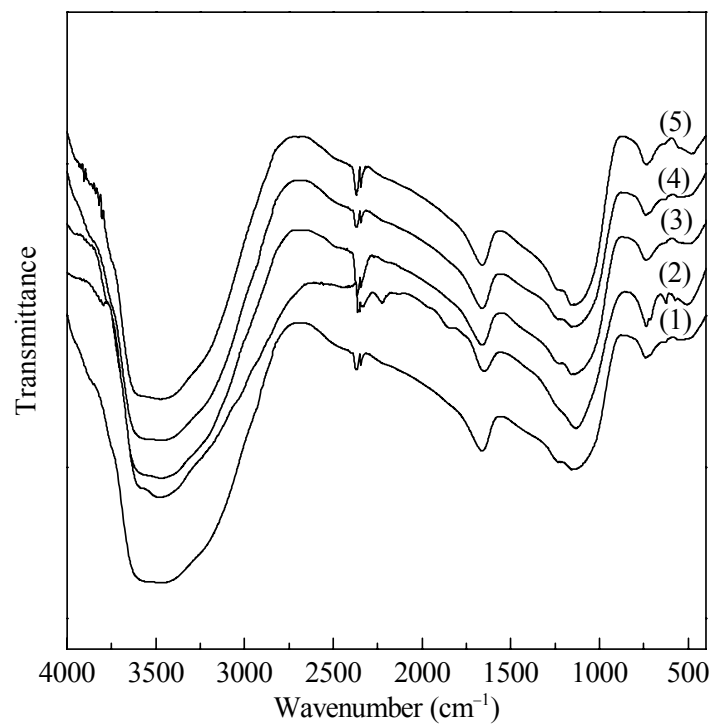

Fig. 2. FT-IR spectra of the calcined CeAlPO-5 samples. (1) CeAlPO-5(25); (2) CeAlPO-5(50); (3) CeAlPO-5(75); (4) CeAlPO-5(100); (5) CeAlPO-5(125).

displayed similar characteristics as that of CeAlPO-5(25), thus established the absence of template.

Table 1 Physico-chemical characteristics of the catalysts

\begin{tabular}{|c|c|c|c|c|c|c|c|c|}
\hline \multirow{2}{*}{ Catalyst } & \multicolumn{3}{|c|}{ As-synthesized } & \multicolumn{3}{|c|}{ Calcined } & \multirow{2}{*}{$\begin{array}{c}\text { BET surface } \\
\text { area }\left(\mathrm{m}^{2} / \mathrm{g}\right)\end{array}$} & \multirow{2}{*}{$\begin{array}{l}\text { Pore volume } \\
\qquad\left(\mathrm{cm}^{3} / \mathrm{g}\right)\end{array}$} \\
\hline & $a=b(\mathrm{~nm})$ & $c / \mathrm{nm}$ & $d_{(100)} / \mathrm{nm}$ & $a=b(\mathrm{~nm})$ & $c / \mathrm{nm}$ & $d_{(100)} / \mathrm{nm}$ & & \\
\hline AlPO-5 & $1.37584 \pm 0.00750$ & $0.84818 \pm 0.01446$ & 1.180 & $1.31561 \pm 0.03631$ & $0.84652 \pm 0.05995$ & 1.135 & 202 & 0.22 \\
\hline CeAlPO-5(25) & $1.36373 \pm 0.00493$ & $0.83856 \pm 0.00551$ & 1.173 & $1.38004 \pm 0.00629$ & $0.81179 \pm 0.13042$ & 1.188 & 215 & 0.28 \\
\hline CeAlPO-5(50) & $1.36772 \pm 0.00037$ & $0.84846 \pm 0.00163$ & 1.183 & $1.38312 \pm 0.00813$ & $0.84443 \pm 0.01630$ & 1.192 & 210 & 0.27 \\
\hline CeAlPO-5(75) & $1.37012 \pm 0.00063$ & $0.85481 \pm 0.00430$ & 1.181 & $1.38860 \pm 0.01148$ & $0.84172 \pm 0.01929$ & 1.195 & 208 & 0.26 \\
\hline CeAlPO-5(100) & $1.37324 \pm 0.00556$ & $0.84819 \pm 0.01022$ & 1.179 & $1.38972 \pm 0.00980$ & $0.8 .3544 \pm 0.02464$ & 1.194 & 205 & 0.25 \\
\hline CeAlPO-5(125) & $1.37096 \pm 0.00488$ & $0.84579 \pm 0.00876$ & 1.176 & $1.38900 \pm 0.01080$ & $0.83632 \pm 0.02789$ & 1195 & 205 & 0.24 \\
\hline
\end{tabular}




\subsubsection{TGA}

The TGA profiles of the as-synthesized CeAlPO-5 samples are shown in Fig. 3. For CeAlPO-5(25), the mass loss below $200{ }^{\circ} \mathrm{C}$ was due to desorption of water. The mass loss between 250 and $450{ }^{\circ} \mathrm{C}$ was due to loss of template. A sharp mass loss at $607{ }^{\circ} \mathrm{C}$ was ascribed to condensation of defective $-\mathrm{OH}$ groups. The total mass loss was about $15 \%$, in which 3\% was assigned to desorption of water and the rest $12 \%$ to loss of template. The thermogram of as-synthesized CeAlPO-5(50) showed similar features as that of CeAlPO-5(25). Desorption of water occurred between 30 and $200{ }^{\circ} \mathrm{C}$, and the removal of template between 200 and $500{ }^{\circ} \mathrm{C}$. The mass loss at 568,650 , and $844{ }^{\circ} \mathrm{C}$ was due to $-\mathrm{OH}$ group condensation. The thermogram of as-synthesized CeAlPO-5(75) exhibited a mass loss due to desorption of water from 30 to $200{ }^{\circ} \mathrm{C}$. But the template decomposed in two stages between 200 and $500{ }^{\circ} \mathrm{C}$. The mass loss due to condensation of $-\mathrm{OH}$ groups occurred at $590{ }^{\circ} \mathrm{C}$. In the thermogram of as-synthesized CeAlPO-5(100), the mass loss below $200{ }^{\circ} \mathrm{C}$ was due to loss of water and that between 200 and $455{ }^{\circ} \mathrm{C}$ was due to template. A slight increase in mass was observed at $590{ }^{\circ} \mathrm{C}$. This is attributed to chemisorption of nitrogen [23]. The thermogram of as-synthesized CeAlPO-5(125) is shown in Fig. 3(5). The mass loss below $200{ }^{\circ} \mathrm{C}$ was due to desorption of water. The loss of template occurred between 200 and $500{ }^{\circ} \mathrm{C}$. A series of mass increase were observed above $500{ }^{\circ} \mathrm{C}$ similar to that of CeAlPO-5(100). Hence, they were assigned to adsorption of nitrogen.

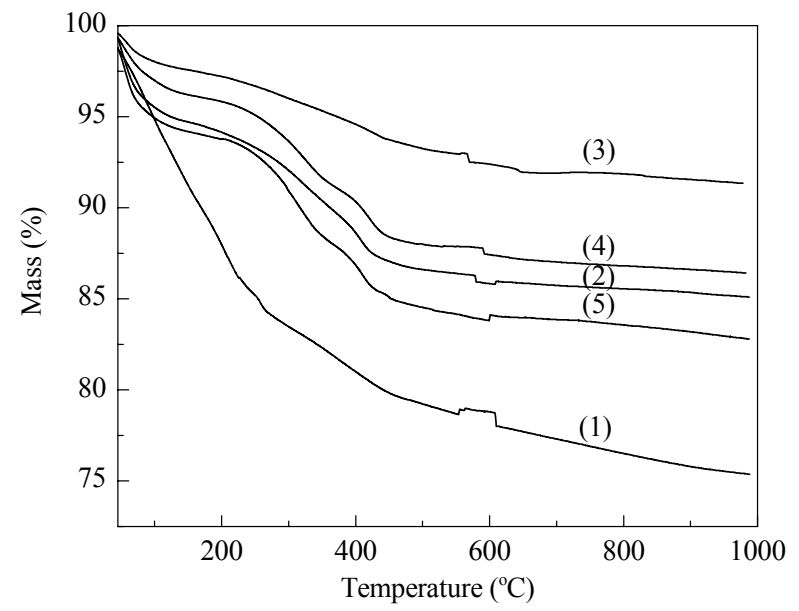

Fig. 3. TGA profiles of the as-synthesized CeAlPO-5 samples $\left(\mathrm{N}_{2}\right.$ atmosphere). (1) CeAlPO-5(25); (2) CeAlPO-5(50); (3) CeAlPO-5(75); (4) CeAlPO-5(100); (5) CeAlPO-5(125).

The TGA and DTG curves of CeAlPO-5(25) calcined in air were recorded in order to establish the temperature at which chemisorption of oxygen occurred. This is important to decide the temperature range over which the vapor phase oxidation of alkyl aromatics can be carried out. The results are illustrated in Fig. 4(a). There was no mass increase observed in these curves to support oxygen chemisorption. The ESR spectrum showed the characteristic peak for $\mathrm{Ce}^{3+}$ and hence the unpaired electron of cerium was not transferred to oxygen at room temperature. Since desorption of oxygen was not noticed at higher temperatures, there must be electron transfer from cerium to oxygen in order to retain them. Cerium might be in the +3 oxidation state at ambient temperature and +4 at high temperature. Although such view was not reported earlier, the present TGA-DTA results confirmed it. The TGA results of other catalysts also exhibited similar behavior. Hence, chemisorption of oxygen occurred in all the catalysts during calcination.
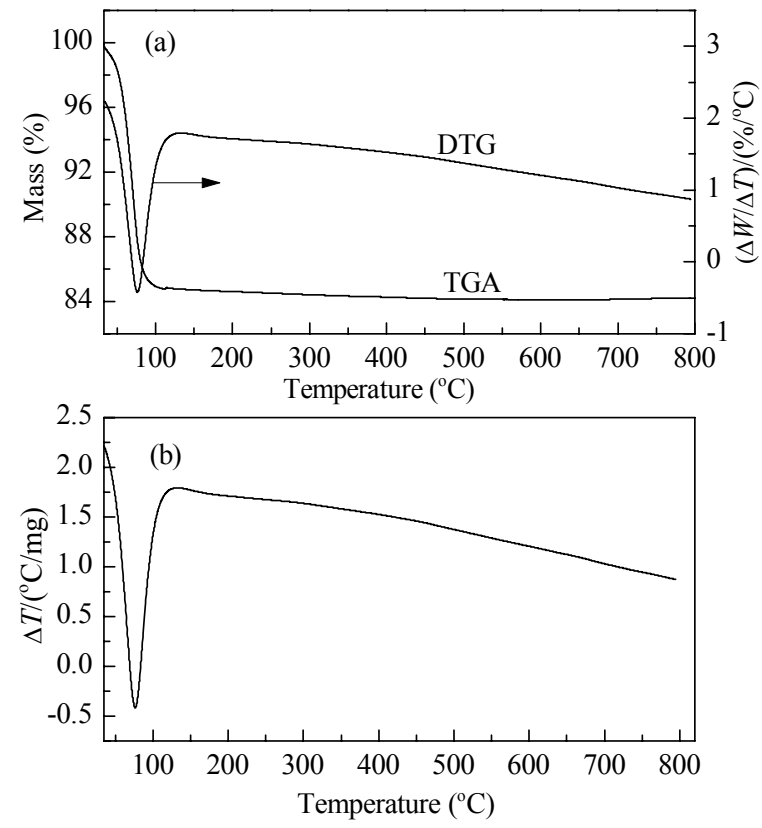

Fig. 4. TGA-DTG (a) and DTA (b) results of the calcined CeAlPO-5(25) (air atmosphere).

The DTA results of calcined CeAlPO-5, shown in Fig. 4(b), also confirmed the absence of oxygen uptake during the analysis, thus supporting again the chemisorption of oxygen only during calcination.

\subsubsection{Nitrogen adsorption-desorption}

The nitrogen adsorption-desorption isotherms of AlPO-5 and CeAlPO-5 molecular sieves are depicted in Fig. 5. All of them exhibited characteristic type III adsorption isotherm. Similar isotherms were also reported in the literature [22]. Since hysterisis was not observed in the adsorption-desorption isotherms of all the catalysts, the absence of mesopores in these catalysts was established. The BET surface area and pore volume derived from the adsorption isotherms are presented in Table 1. Cerium incorporated 


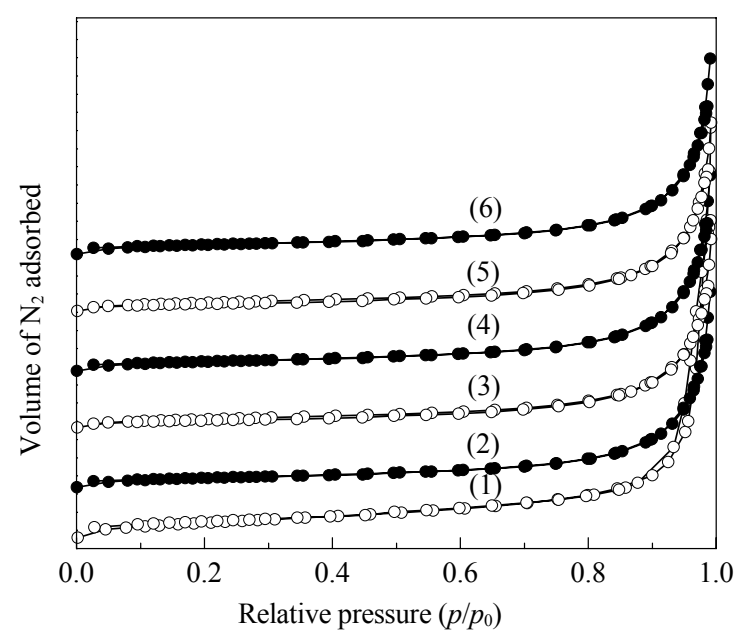

Fig. 5. Nitrogen adsorption-desorption isotherms of AlPO-5 and CeAlPO-5. (1) AlPO-5; (2) CeAlPO-5(25); (3) CeAlPO-5(50); (4) CeAlPO-5(75); (5) CeAIPO-5(100); (6) CeAlPO-5(125).

AlPO-5 molecular sieves showed higher surface area than the parent AlPO-5, which supported the framework incorporation of cerium. Since the ionic radius of cerium $(0.137$ $\mathrm{nm})$ is larger than that of aluminium $(0.053 \mathrm{~nm})$, such variation in surface area is an expected one. The pore volume of cerium substituted molecular sieves was slightly higher than that of AlPO-5 [22]. This also supported the incorporation of cerium into the framework. Thus, increase of surface area and pore volume, and the variation of lattice parameters supported incorporation of cerium into the framework.

\subsubsection{UV-Vis DRS}

The UV-Vis DRS spectra of the as-synthesized CeAlPO-5 samples are shown in Fig. 6(a). All the spectra showed an

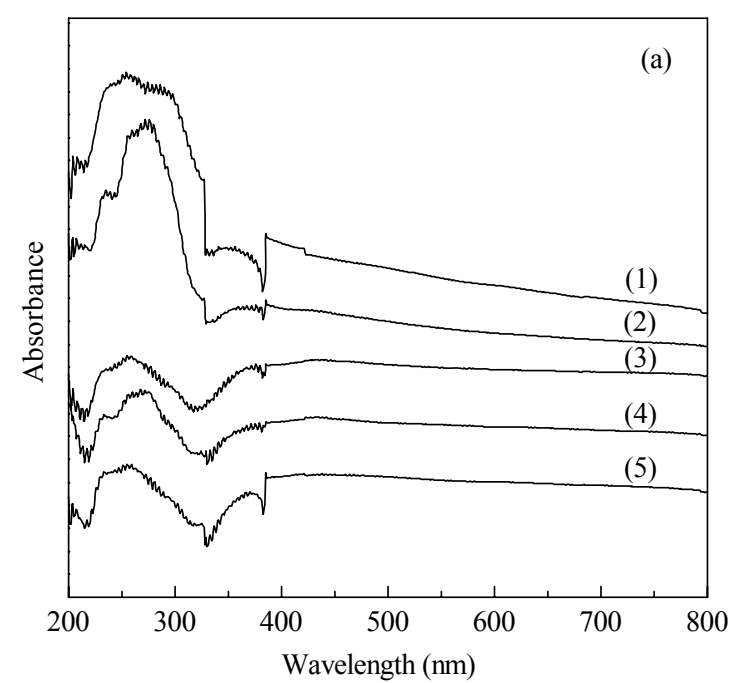

intense absorbance maximum close to $250 \mathrm{~nm}$. This is assigned to $\mathrm{O}^{2-} \rightarrow \mathrm{Ce}^{3+}$ charge transfer transition of framework cerium [22]. It was reported that $\mathrm{CeO}_{2}$ exhibited an absorption maximum around $370 \mathrm{~nm}$ [24] for band gap excitation, but such absorption maximum was absent in the spectra. Hence, it is presumed that separate ceria phase was absent. This also established the incorporation of cerium in the framework. The absorption maximum of framework cerium gradually decreased with increase in $\mathrm{Al} / \mathrm{Ce}$ ratios. The UV-Vis DRS spectra of calcined CeAlPO-5 are shown in Fig. 6(b). For CeAlPO-5(25), the absorbance maximum of framework $\mathrm{Ce}^{3+}$ was very much shifted towards longer wavelength. There were also shoulders close to charge transfer band of framework $\mathrm{Ce}^{3+}$. This observation revealed different environment for $\mathrm{Ce}^{3+}$ in CeAlPO-5(25). In other words, the four oxidic sites around the framework cerium may not be equidistant in all $\mathrm{Ce}^{3+}$ sites. This may arise if cerium sites are located in different regions.

All the spectra of the calcined CeAlPO-5 $(x=50,75$, 100 , and 125) displayed features similar to that of CeAlPO-5(25). Hence, it was presumed that free $\mathrm{Ce}_{2} \mathrm{O}_{3}$ [24] and $\mathrm{CeO}_{2}$ [25] were absent in all the materials. In other words, cerium was not leached out from the framework of CeAlPO-5 during calcination.

\subsubsection{Raman spectroscopy}

The Raman spectra of the calcined CeAlPO-5(25) and CeAlPO-5(50) are shown in Fig. 7. A sharp weak scattering was observed around $300 \mathrm{~cm}^{-1}$ in both the spectra. It was assigned to framework $\mathrm{Ce}-\mathrm{O}$ vibration. The non-framework ceria vibration was reported to yield a peak between 460 and $465 \mathrm{~cm}^{-1}$ due to triply degenerate $F_{2 \mathrm{~g}}$ mode $[21,26]$. As this peak was absent in both the spectra, absence of

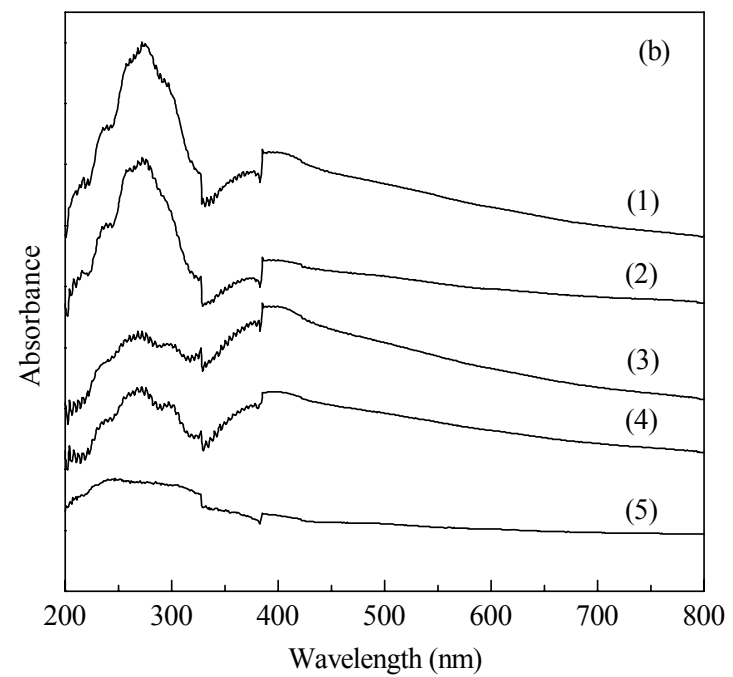

Fig. 6. UV-Vis DRS spectra of the as-synthesized (a) and calcined (b) CeAlPO-5. (1) CeAlPO-5(25); (2) CeAlPO-5(50); (3) CeAlPO-5(75); (4) CeAlPO-5(100); (5) CeAlPO-5(125). 


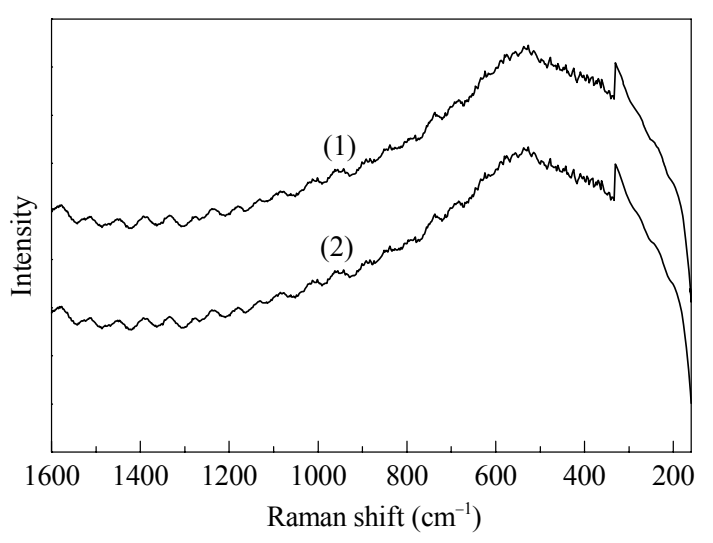

Fig. 7. Raman spectra of the calcined CeAlPO-5(25) (1) and CeAlPO-5(50) (2).

non-framework ceria was confirmed. Hence the entire cerium might be incorporated in the framework.

\subsubsection{SEM}

The SEM images of the calcined CeAlPO-5 samples are shown in Fig. 8. The images displayed large hexagonal rods with tiny crystallites on their surface $[21,22]$. The amount of tiny crystallites decreased with increase in $\mathrm{Al} / \mathrm{Ce}$ ratios. The presence of tiny crystallites indicated insufficient crystallization time and slow crystallization process. This is attributed to the incorporation of cerium in the framework. As $\mathrm{Ce}^{3+}$ is larger in size $(0.137 \mathrm{~nm})$ than $\mathrm{Al}^{3+}(0.053 \mathrm{~nm})$, its incorporation into the framework is difficult in comparison to aluminium. In addition, the large size of cerium could slow down the rate of reaction of its hydroxide with phosphate. This might be the cause for the appearance of tiny crystallites on the surface of hexagonal rods. This analysis also established the difficulty in the incorporation of metal ions of larger size into the framework AlPO-5 during crystallization.

\subsubsection{ESR}

The ESR spectrum of the calcined CeAlPO-5(25) is shown in Fig. 9. The broad envelope at $g=2.0$ was due to chemisorbed oxygen on cerium [27]. The chemisorbed oxygen carries an unpaired electron for which an ESR signal was observed. The broad unsymmetrical signal with $g$ value between 1.1 and 2.4 indicated highly unsymmetrical environment of $\mathrm{Ce}^{3+}$. As a result of chemisorption, $\mathrm{Ce}^{3+}$ is not oxidized to $\mathrm{Ce}^{4+}$ since there was no evidence for $\mathrm{Ce}^{4+}$ in

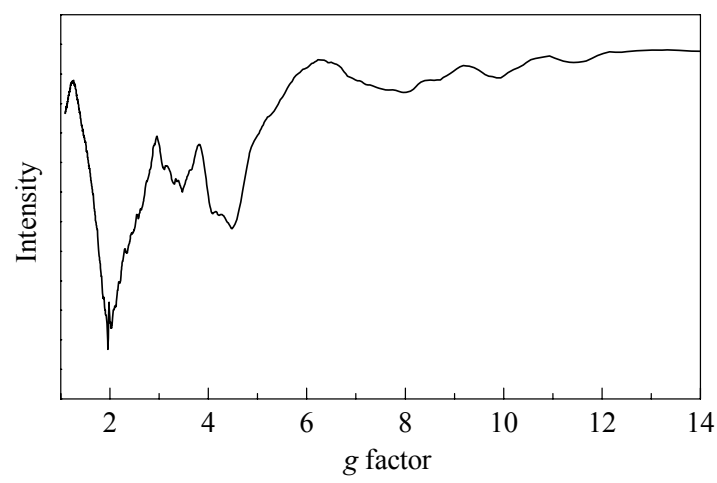

Fig. 9. ESR spectrum of the calcined CeAlPO-5(25).
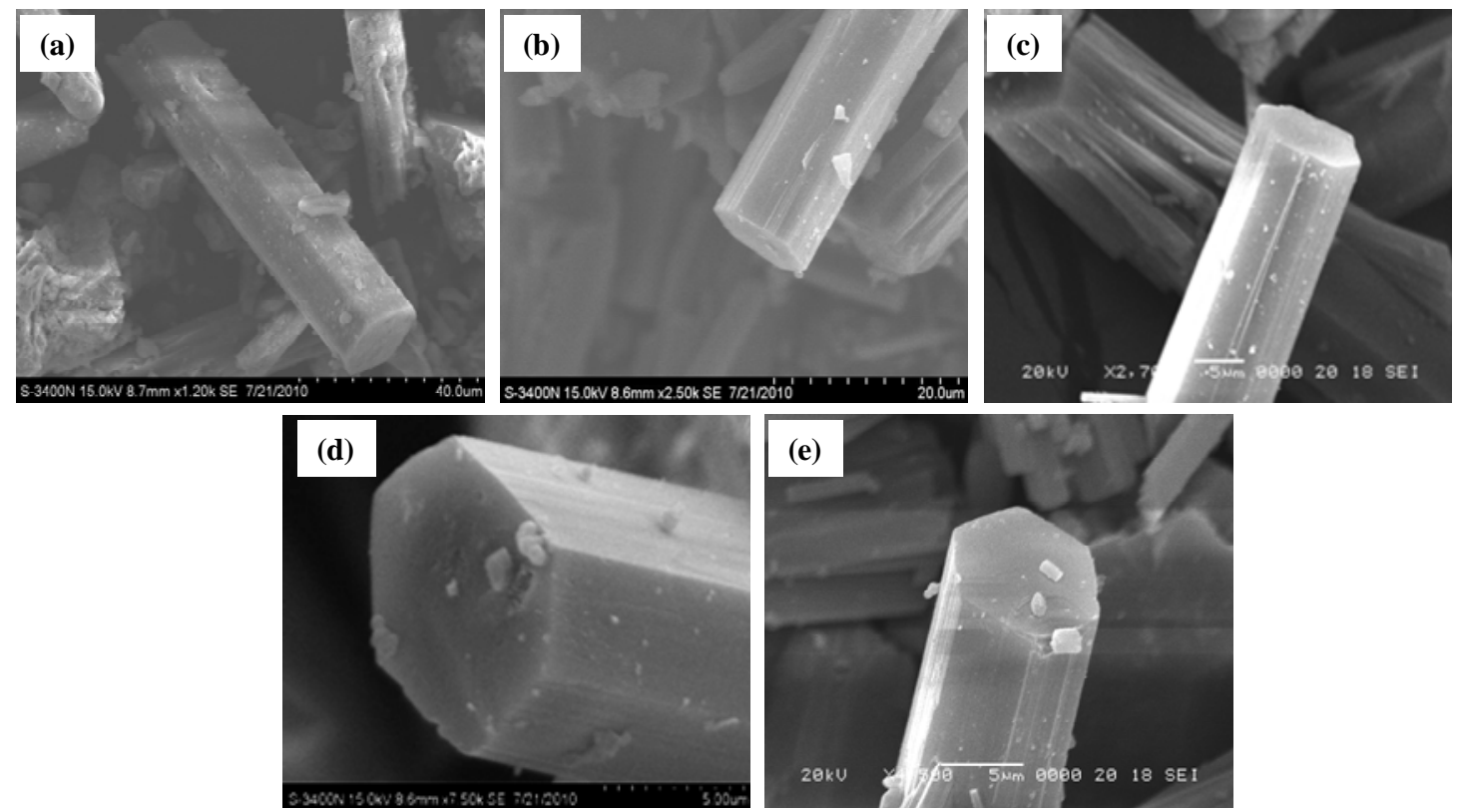

Fig. 8. SEM images of the calcined CeAlPO-5 samples. (a) CeAlPO-5(25); (b) CeAlPO-5(50); (c) CeAlPO-5(75); (d) CeAlPO-5(100); (e) CeAlPO-5(125). 
the UV-Vis DRS spectra. There were also other signals observed above $g=2.4$. The extra peaks in the ESR spectrum with high $g$ values could be ascribed to $\mathrm{Ce}^{3+}$ with different environment as discussed in the UV-Vis DRS study. It could lead to either expansion or contraction of $4 f$ orbitals by which $g$ values could be altered. Although the nuclear spin quantum of cerium is $5 / 2$, hyperfine lines were completely masked.

\subsubsection{XPS}

The XPS spectrum of CeAlPO-5(25), shown in Fig. 10, demonstrated similar features as that of the XPS spectrum reported by Zhao et al. [21]. There was no evidence for the presence of $\mathrm{Ce}^{4+}$ sites, which was also confirmed from UV-Vis DRS and ESR analyses. Hence, $\mathrm{Ce}^{3+}$ alone might be present in the framework. The first peak between 878 and $890 \mathrm{eV}$ was assigned to Ce $3 d_{5 / 2}$ state and the other between 895 and $910 \mathrm{eV}$ to $\mathrm{Ce} 3 d_{3 / 2}$ state [28].

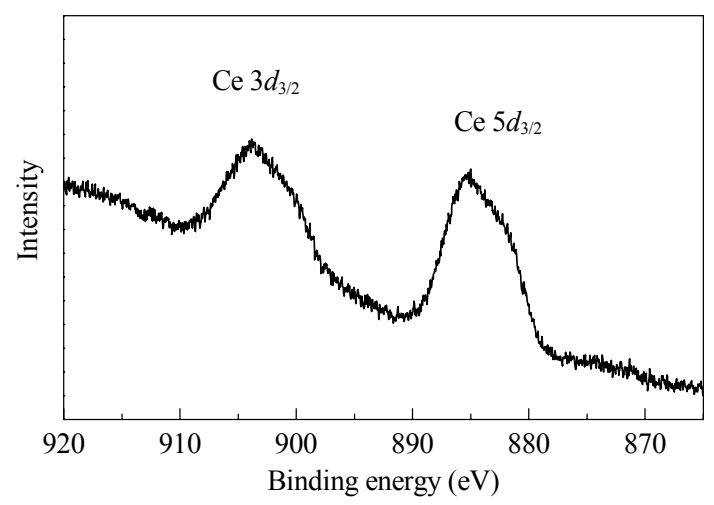

Fig. 10. XPS spectrum of the calcined CeAlPO-5(25).

\subsection{Catalytic studies}

\subsubsection{Effect of temperature}

The vapor phase oxidation of DPM over CeAlPO-5(25) was carried out. Since air oxidation of DPM without the catalyst occurred significantly at $350{ }^{\circ} \mathrm{C}$, the catalytic oxidation was studied only between 250 and $325^{\circ} \mathrm{C}$. The product analysis confirmed benzophenone as the major product and diphenylmethanol as the only minor product. The results of DPM conversion and product selectivity are shown in Fig. 11. The reaction was also conducted over parent AlPO-5 at $250{ }^{\circ} \mathrm{C}$, but the conversion of diphenylmethane was not significant.

The conversion increased with increase in temperature. Since benzophenone was the major product, its precursor, viz., diphenylmethanol might be rapidly oxidized to the final product. The sequence of reactions in the oxidation is illustrated in Scheme 1. Oxygen is chemisorbed on $\mathrm{Ce}^{3+}$

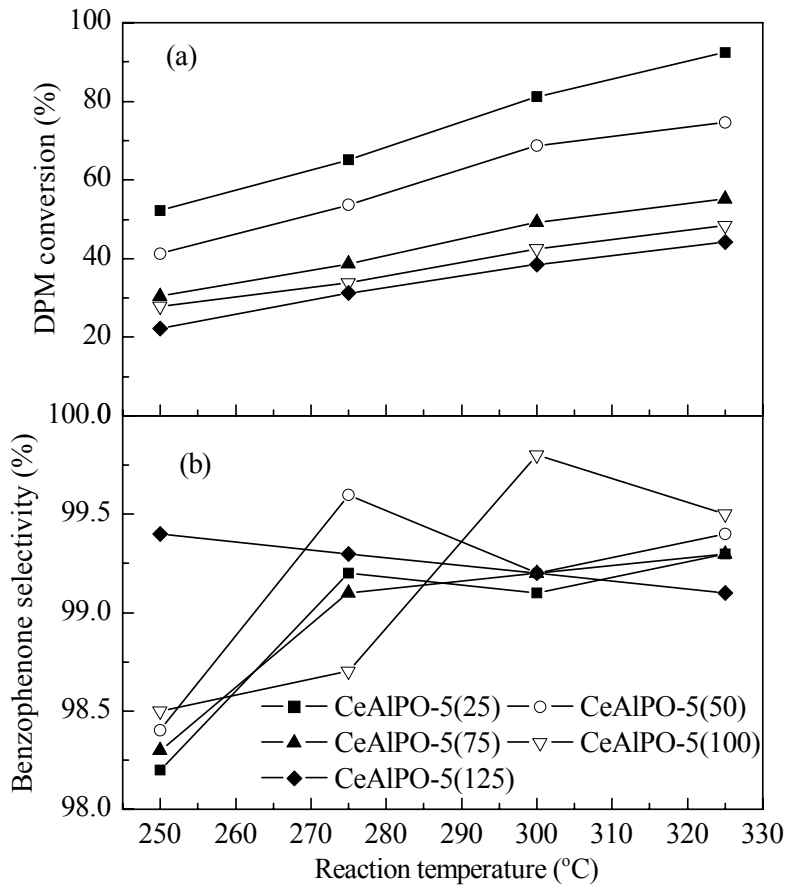

Fig. 11. Effect of temperature on DPM conversion (a) and benzophenone selectivity (b). Reaction conditions: catalyst $0.5 \mathrm{~g}$, feed rate 2 $\mathrm{ml} / \mathrm{h}$, air flow rate $7 \mathrm{ml} / \mathrm{min}$, WHSV $=4.024 \mathrm{~h}^{-1}$.

sites present in CeAlPO-5 molecular sieve. When the vapor of DPM pass close to the chemisorbed oxygen on $\mathrm{Ce}^{3+}$ sites in CeAlPO-5, the distant oxygen abstracts a hydrogen from the $-\mathrm{CH}_{2}-$ group of DPM to form diphenylmethyl radical. The metal hydroperoxide rapidly transfers its $-\mathrm{OH}$ group of diphenylmethyl radical to form diphenylmethanol. The resulting metal oxy radical rapidly abstracts the hydrogen of diphenylmethanol to form diphenylmethanol radical, and the latter radical rapidly releases a hydrogen atom to form benzophenone. The metal hydroxy group and the hydrogen atom combine to form water. Hence this oxidation is a selective one. The selectivity for benzophenone was above $99 \%$ and it remained the same with increase in temperature.

The results of oxidation over CeAlPO-5 ( $x=50,75,100$,

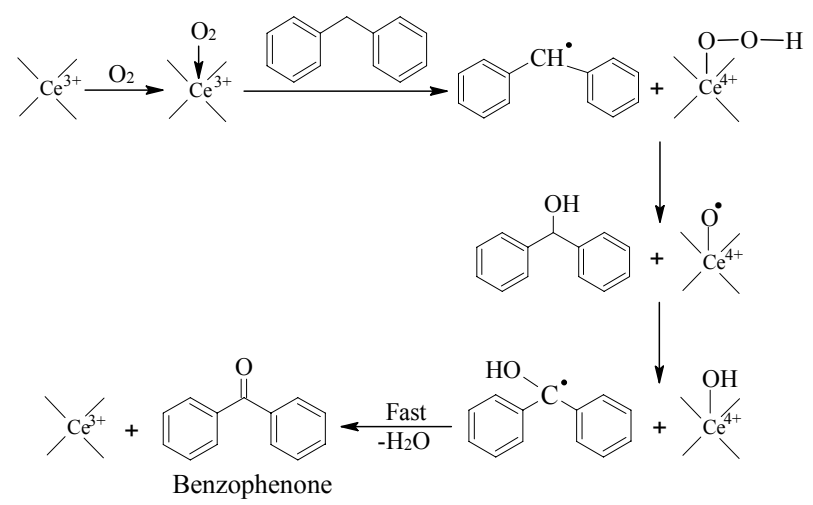

Scheme 1. Plausible pathway for the oxidation of diphenylmethane. 
and 125) also exhibited nearly similar trend as that of CeAlPO-5(25). But over these catalysts, the conversion was found to be lower than that of CeAlPO-5(25) at each temperature. Hence, it is clear that the density of active sites is the main parameter which controls conversion.

The order of catalytic activity followed the order of cerium content in the catalysts. All other catalysts showed high selectivity for benzophenone as that of CeAlPO-5(25). Although the cerium content in these catalysts was less than CeAlPO-5(25), the same selectivity for benzophenone was confirmed. This revealed the sequence of oxidation of DPM to diphenylmethanol and then to benzophenone on the same chemisorbed oxygen molecule. Based on the DPM conversion and product selectivity, CeAlPO-5(25) was proved to be more active than CeAlPO-5 $(x=50,75,100$, and 125) catalysts. The optimum temperature for maximum conversion with high selectivity was found to be $325^{\circ} \mathrm{C}$. In order to optimize the air flow rate, the flow rate was varied, and the results are presented in Table 2 .

Table 2 Effect of air flow rate on DPM conversion and benzophenone selectivity over CeAlPO-5(25)

\begin{tabular}{cccc}
\hline \multirow{2}{*}{$\begin{array}{c}\text { Air flow rate } \\
(\mathrm{ml} / \mathrm{min})\end{array}$} & $\begin{array}{c}\text { DPM conversion } \\
(\%)\end{array}$ & \multicolumn{2}{c}{ Selectivity (\%) } \\
\cline { 3 - 4 } & 93.2 & 99.1 & 0.9 \\
6 & 97.4 & 99.2 & 0.8 \\
7 & 92.2 & 99.1 & 0.9 \\
8 & 86.5 & 99.0 & 1.0 \\
\hline
\end{tabular}

Reaction conditions: catalyst $0.5 \mathrm{~g}$, temperature $325^{\circ} \mathrm{C}$, feed rate 2 $\mathrm{ml} / \mathrm{h}, \mathrm{WHSV}=4.024 \mathrm{~h}^{-1}$.

The conversion of DPM increased when the air flow was increased from 5 to $6 \mathrm{ml} / \mathrm{min}$ and beyond this flow rate of air, the conversion decreased, thus indicating $6 \mathrm{ml} / \mathrm{min}$ as the optimum air flow rate. But the selectivity for benzophenone remained the same irrespective of the air flow rate, which confirmed the use of both oxygen atoms of the same chemisorbed molecule for the oxidation as explained above. The influence of DPM feed rate $(2,3,4,5$, and $6 \mathrm{ml} / \mathrm{h}$ ) was studied and the results are depicted in Fig. 12. With the increase in the feed rate, conversion of DPM decreased although the selectivity for benzophenone remained nearly the same. The results revealed that $2 \mathrm{ml} / \mathrm{h}$ is the optimum one. The effect of WHSV on conversion and product selectivity are presented in Table 3.

The reaction was also carried out by using freshly prepared ceria $\left(\mathrm{CeO}_{2}\right)$ catalyst under the same conditions. $\mathrm{CeO}_{2}$ was prepared by calcination of cerium nitrate hexahydrate at $550{ }^{\circ} \mathrm{C}$ in air for $12 \mathrm{~h}$. The XRD pattern of $\mathrm{CeO}_{2}$, shown in Fig. 13, exhibited the characteristic peaks of $\mathrm{CeO}_{2}$ [29]. The oxidation of DPM over $\mathrm{CeO}_{2}$ with air as oxidant revealed almost negligible conversion. Hence, the oxidation of DPM

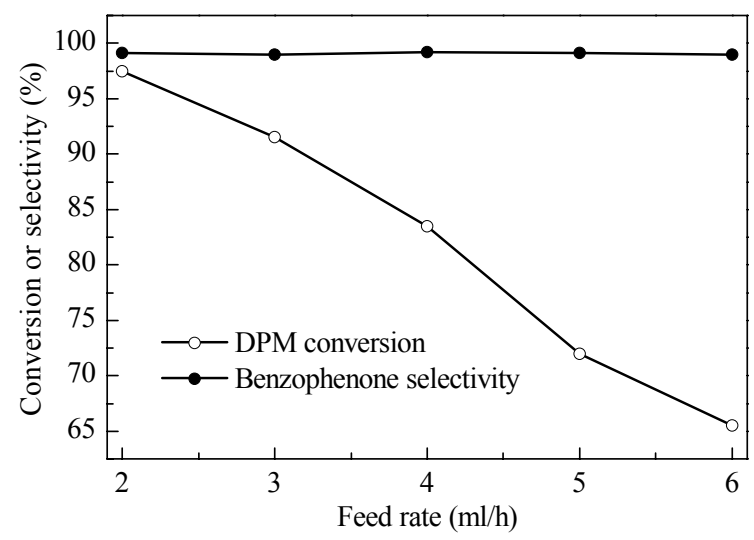

Fig. 12. Effect of feed rate on DPM conversion and benzophenone selectivity over CeAlPO-5(25). Reaction conditions: catalyst $0.5 \mathrm{~g}$, temperature $325^{\circ} \mathrm{C}$, air flow rate $6 \mathrm{ml} / \mathrm{min}$, WHSV $=4.024 \mathrm{~h}^{-1}$.

Table 3 Effect of WHSV on DPM conversion and benzophenone selectivity over CeAlPO-5(25)

\begin{tabular}{cccc}
\hline \multirow{2}{*}{$\begin{array}{c}\text { WHSV } \\
\left(\mathrm{h}^{-1}\right)\end{array}$} & $\begin{array}{c}\text { DPM conversion } \\
(\%)\end{array}$ & \multicolumn{2}{c}{ Product selectivity (\%) } \\
\cline { 3 - 4 } 4.0240 & 97.4 & 99.1 & 0.9 \\
6.0386 & 91.5 & 99.0 & 1.0 \\
8.0450 & 83.5 & 99.2 & 0.8 \\
10.060 & 71.6 & 99.1 & 0.9 \\
12.077 & 65.2 & 99.0 & 1.0 \\
\hline
\end{tabular}

Reaction conditions: catalyst $0.5 \mathrm{~g}$, temperature $325{ }^{\circ} \mathrm{C}$, feed rate 2 $\mathrm{ml} / \mathrm{h}$; air flow rate $6 \mathrm{ml} / \mathrm{min}$.

was established due to $\mathrm{Ce}^{3+}$ sites in CeAlPO-5(25). As this process required oxygen for oxidation, $\mathrm{Ce}^{3+}$ could adsorb and activate oxygen whereas $\mathrm{Ce}^{4+}$ is incapable of adsorption of oxygen. Though $\mathrm{CeO}_{2}$ was proved to be absent in the synthesized catalysts, even if present, it might be incapable of activating oxygen for the oxidation of DPM.

\subsubsection{Effect of time on stream}

The effect of time on stream on DPM conversion and

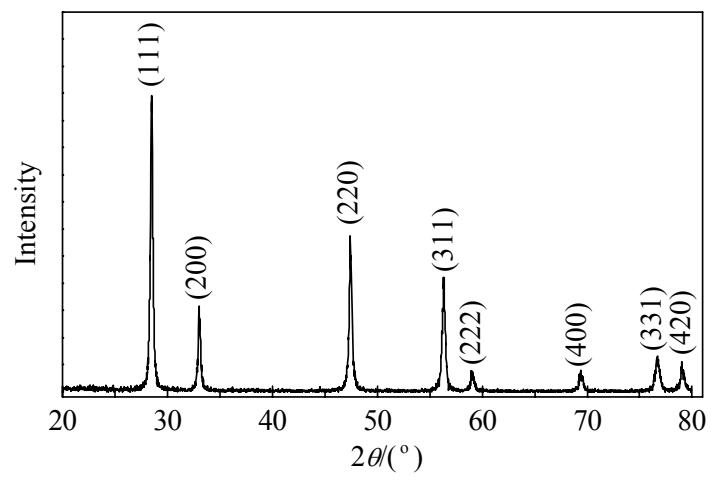

Fig. 13. XRD pattern of $\mathrm{CeO}_{2}$. 
product selectivity was tested for $6 \mathrm{~h}$ over CeAlPO-5(25) and the results are presented in Table 4 . The conversion and product selectivity remained the same throughout the time on stream, thus confirming the absence of leaching of $\mathrm{Ce}^{3+}$ sites from the framework. Further, the sequence of reactions might be same during the entire period of time on stream. Since selectivity for benzophenone remained the same, the same mechanism of oxidation prevailed throughout the time on stream. This also proved the stability of catalysts and absence of coke formation. The amount of feed was nearly equal to the amount of product formed which also established the absence of coke formation. The same study was carried out 3 times and the spent catalyst was characterized by XRD at the end of third time after calcination. The XRD results were same as that of the original catalysts illustrating catalyst stability. Since the patterns showed similar features as that of the fresh catalyst and hence leaching of $\mathrm{Ce}^{3+}$ from the framework was ruled out. The catalyst was activated after use at $500{ }^{\circ} \mathrm{C}$ and then reused for the reaction. It was found that the catalyst was not only stable but also yielded nearly the same conversion and selectivity for three cycles.

Table 4 Effect of time on stream on DPM conversion and benzophenone selectivity over CeAlPO-5(25)

\begin{tabular}{cccc}
\hline \multirow{2}{*}{$\begin{array}{c}\text { Time } \\
\text { (h) }\end{array}$} & DPM conversion & \multicolumn{2}{c}{ Selectivity (\%) } \\
\cline { 3 - 4 }$(\%)$ & Benzophenone & Diphenylmethanol \\
\hline 1 & 97.1 & 99.2 & 0.8 \\
2 & 98.3 & 99.2 & 0.8 \\
3 & 97.5 & 99.1 & 0.9 \\
4 & 98.4 & 99.0 & 1.0 \\
5 & 96.3 & 99.2 & 0.8 \\
6 & 98.2 & 99.1 & 0.9 \\
\hline
\end{tabular}

Reaction conditions: catalyst $0.5 \mathrm{~g}$, temperature $325^{\circ} \mathrm{C}$, feed rate 2 $\mathrm{ml} / \mathrm{h}$, air flow rate $6 \mathrm{ml} / \mathrm{min}$.

\section{Conclusions}

The synthesis of CeAlPO-5 molecular sieves in fluoride medium was successful. The characterization revealed the absence of non-framework ceria in all the catalysts. The framework incorporation of cerium was established by XRD and UV-Vis DRS studies. Oxidation via activation of oxygen adsorption was evident. The ESR study proved the absence of oxidation of $\mathrm{Ce}^{3+}$ to $\mathrm{Ce}^{4+}$ at room temperature although adsorption of oxygen on $\mathrm{Ce}^{3+}$ established single site CeAlPO-5 molecular sieves are effective catalyst for selective oxidation of diphenylmethane to benzophenone. Though active cerium site isolation is a requirement for selective oxidation, the magnetic field of cerium sites and free radicals produced during oxidation were also suggested to play a major role in the selective oxidation. In addition, free rotation across the phenyl and ethyl carbon bond also suggested to be a key factor for selective oxidation of diphenylmethane. The time on stream study revealed the stability of the catalysts.

\section{References}

1 Bauer K, Garbe D, Surberg H. Common Fragrance and Flavor Materials. Weinheim: WHC Vertagsgesellschaft, 1990. 83

2 Khadilkar B M, Borkar S D. Tetrahedron Lett, 1997, 38: 1641

3 Tagawa T, Amemiya J, Goto S. Appl Catal A, 2004, 257: 19

4 Jacob B, Sugunan S, Singh A P. J Mol Catal A, 1999, 139: 43

5 Patil P T, Malshe K M, Kumar P, Dongare M K, Kemnitz E. Catal Commun, 2002, 3: 411

6 Bezouhanova C P. Appl Catal A, 2002, 229: 127

7 Mardani H R, Golchoubian H. J Mol Catal A, 2006, 259: 197

8 Clark J H, Kybett A P, London P, Macquarrie D J, Martin K. J Chem Soc, Chem Commun, 1989: 1355

9 Shaabani A, Bazgir A, Teimouri F, Lee D G. Tetrahedron Lett, 2002, 43: 5165

10 Oussaid A, Loupy A. J Chem Res S, 1997: 342

11 Silvestre S M, Salvador J A R. Tetrahedron, 2007, 63: 2439

12 Caps V, Tsang S C. Catal Today, 2000, 61: 19

13 Jha R K, Shylesh S, Bhoware S S, Singh A P. Microporous Mesoporous Mater, 2006, 95: 154

14 Tang L, Li B, Zhai Z, Li J, Ou E, Wang J. Catal Lett, 2008, 121: 63

15 Chang F, Li W, Xia F, Yan Z, Xiong J, Wang J. Chem Lett, 2005, 34: 1540

16 Choudhary V R, Indurkar J R, Narkhede V S, Jha R. J Catal, 2004, 227: 257

17 Kishore D, Rodrigues A E. Catal Commun, 2009, 10: 1212

18 De Klein W J, Mils W J, De Jonge C R H. Organic Synthesis by Oxidation with Metal Compounds. New York: Plenum, 1986. 261

19 Molander G A. Chem Rev, 1992, 92: 29

20 Yu C L, Ge Q J, Xu H Y, Li W Z. Appl Catal A, 2006, 315: 58

21 Zhao R, Wang Y Q, Guo Y, Guo Y L, Liu X H, Zhang Z G, Wang Y S, Zhan W C, Lu G Z. Green Chem, 2006, 8: 459

22 Li J, Li X, Shi Y, Mao D S, Lu G Z. Catal Lett, 2010, 137: 180

23 Nayak V S. J Phys Chem, 1992, 96: 8690

24 Yuliati L, Hamajima T, Hattori T, Yoshida H. Chem Commun, 2005: 4824

25 Li F B, Li X Z, Hou M F, Cheah K W, Choy W C H. Appl Catal A, 2005, 285: 181

26 Lin X M, Li L P, Li G S, Su W H. Mater Chem Phys, 2001, 69: 236

27 El-Mallawany R, El-Sayed A H, El-Gawad M M H A. Mater Chem Phys, 1995, 41: 87

28 Burroughs P, Hamnett A, Orchard A F, Thornton G. J Chem Soc, Dalton Trans, 1976: 1686

29 Zhang G, Shen Z, Liu M, Guo C, Sun P, Yuan Z, Li B, Ding D, Chen T. J Phys Chem B, 2006, 110: 25782 